\title{
A Friendly Police Supervision Model and Youth Violence Reduction in Northern Saskatchewan: Implications for Indigenous Policing in Canada
}

\author{
Davut Akca $^{1}$ D . Lisa M. Jewell ${ }^{2}$
}

Received: 26 July 2021 / Accepted: 19 January 2022 / Published online: 1 February 2022

(c) The Author(s), under exclusive licence to Springer Nature Switzerland AG 2022

\begin{abstract}
Indigenous policing has become a prominent concept which refers to an institutional transformation in the Canadian policing perspective based on the recognition of rights, respect, cooperation, and reconciliation. Despite increasing prominence of the Indigenous policing concept, there is limited scholarly attention to this area. Research can contribute to the efforts to develop culturally responsive and effective policing methods within Indigenous communities. The Northeast Youth Violence Reduction Partnership (NYVRP), a five-year pilot project (2015-2020), was implemented in three predominantly Indigenous communities in Northeastern Saskatchewan which have high police-reported crime rates to reduce offending among youth at risk for violence or gang involvement $(n=84)$. One of the main components of the NYVRP was the friendly supervision model of the police to maintain a positive relationship with youth rather than an adversarial relationship. To assess the achievements of the program, process and outcome evaluations were conducted. Findings provided evidence concerning the relevance of the friendly police supervision model with the overall goals of the program as well as the effectiveness of this model to reduce violence in the communities and indicated the ongoing need to develop better relationships between the police and Indigenous communities and youth. The evaluation findings on the process and impact of the program in terms of the policing components and the role of the police are shared and the implications of these findings for Indigenous policing approaches are discussed in light of best practices from other jurisdictions.
\end{abstract}

Keywords Indigenous policing $\cdot$ Youth Violence Reduction $\cdot$ Friendly supervision $\cdot$ Community-based programs

In parallel with the rising tensions between Black communities and the U.S. police after the death of George Floyd, there has been an increasing number of protests and public unrest in Canada upon some serious conflicts between the police and members of Indigenous communities. It is reported that more than one-third of the people shot to death by Royal Canadian Mounted Police (RCMP) officers between 2007 and 2017 were Indigenous (Freeze, 2019). In 2020, the shooting of six Indigenous people by police and a video of a First Nations chief being beaten by RCMP officers that went viral around the same period fueled the debate

Davut Akca

dakca@lakeheadu.ca

1 Faculty of Social Sciences and Humanities, Lakehead University, Orillia, ON, Canada

2 Centre for Forensic Behavioural Science and Justice Studies, University of Saskatchewan, Saskatoon, SK, Canada over systemic racism and "defunding the police" in Canada (Graham, 2020).

Policing of Indigenous communities has been debated for almost a century and is one of the core aspects of the discussions on the relationship between the Canadian government and Indigenous people. A history of being colonized and forced attendance at residential schools, as well as the power imbalances and social and economic conditions that have resulted from these practices, have led to numerous problems among Indigenous communities, including overrepresentation in the incarcerated population, mistrust between Indigenous people and the government agencies, intergenerational trauma, substance abuse, and mental health problems (Chouinard \& Cousins, 2007; Monchalin, 2016; Stewart \& Dene, 2009). The fact that the RCMP, the national police agency of Canada, was used by the Canadian governments to enforce some colonial policies, including the removal of Indigenous youth from their communities and placement in residential schools, led to a substantial erosion in Indigenous 
people's trust toward Canadian police (LeBeuf, 2011). In addition to these historical grievances, Indigenous people are also currently over-policed (i.e., they are singled out by the police during regular policing activities, stereotyped as criminals or gang members, charged disproportionately by the police, or generally harassed) or under-policed (i.e., they are ignored when it comes to crime prevention or victim support, especially within the context of missing and murdered Indigenous women and girls; Monchalin, 2016).

In light of the lessons learned from the historical events and recent developments, a call for a new Indigenous policing model is long overdue. On a positive note, there has been substantial efforts to better meet the needs of Indigenous communities and reduce the level of violence and crime through community-based, culturally sensitive approaches and programs. The Northeast Youth Violence Reduction Partnership (NYVRP), a 5-year pilot project (2015-2020), was such a program implemented in three predominantly Indigenous communities in Northeastern Saskatchewan which have high police-reported crime rates to reduce offending among youth at risk for violence or gang involvement. One of the main components of the NYVRP was the friendly supervision model of the police to maintain a positive relationship with youth rather than an adversarial relationship. To assess the achievements of the program, we conducted process and outcome evaluations. In this study, the evaluation findings on the process and impact of the program in terms of the policing components and the role of the police in the program will be shared and the implications of these findings for Indigenous policing approaches will be discussed in light of best practices from other jurisdictions.

\section{Indigenous Policing}

Indigenous policing has become a prominent concept within the reconciliation process with Indigenous peoples. Overall, the concept of Indigenous policing refers to an institutional transformation in the Canadian policing perspective based on the recognition of rights, respect, cooperation, and reconciliation. In this context, Canadian police departments aim to develop practical and culturally responsive policing services for Indigenous communities (Public Safety Canada, 2021). Indeed, the framework of Indigenous policing was first officially drawn with the development of the First Nations Policing Policy (FNPP) by the federal government in 1992 (Ruddell \& Lithopoulos, 2013). Accordingly, the FNPP aimed to provide First Nations and Inuit communities with professional and culturally appropriate policing. Since then, policing services have been delivered through two main models in Indigenous communities: (1) Self-administered agreements which enable a First Nation or Inuit community to manage its own police force under provincial legislation; and (2) Community Tripartite Agreements through which the existing Canadian police forces, such as the RCMP or Ontario Provincial Police, are contracted to provide policing services to a First Nation or Inuit community.

Despite the initial good intentions, the delivery of police services in Indigenous communities continues to suffer from various shortcomings including not being considered "essential services," receiving less funding than their municipal counterparts, and not recognizing the impacts of colonialism and being culturally sensitive (Public Safety Canada, 2016; Ruddell \& Kiedrowski, 2020). In the final report of the National Inquiry into Missing and Murdered Indigenous Women and Girls (2019), a series of recommendations were provided to improve Indigenous policing in Canada: (1) building a civilian oversight body to audit Indigenous police services and investigate claims of police misconduct; (2) enhancement of the relationships between the police and Indigenous peoples; (3) ensuring the delivery of culturally appropriate policing services; (4) increasing recruitment of Indigenous peoples for policing; (5) developing investigative tools, including specialized and traumainformed questioning techniques, for Indigenous people; and (6) building capacity and partnership with other agencies working in Indigenous communities to address crime and related social problems.

Research can contribute to the efforts to develop culturally responsive and effective policing methods within Indigenous communities. However, despite increasing prominence of the Indigenous policing concept, there is limited scholarly attention to this area. Research on Indigenous policing in Canada has been one of the least focused aspects of Canadian law enforcement and arguably the least funded policing topic in Canada (Ruddell \& Lithopoulos, 2013; Ruddell \& Kiedrowski, 2020). Ruddell and Lithopoulos (2013) reviewed decades of developments in the Indigenous policing field in Canada and identified three broad needs for research on Indigenous policing in Canada including the development of a research-based inventory of best practices, evaluation of the efficacy of policing in Indigenous communities, and consideration of the ways in which the study of Indigenous policing can inform organizational theory. In addition, the limited research in the field has mostly focused on urban issues and there is a gap in the literature in terms of the rural aspects of Indigenous policing. Indeed, we know very little about "what works" in Indigenous policing in remote communities (Jones et al., 2014).

\section{NYVRP}

The NYVRP, a 5-year pilot project (2015-2020), was implemented in three predominantly Indigenous communities in Northeastern Saskatchewan which have high police-reported 
crime rates to reduce offending among youth at risk for violence or gang involvement (Jewell et al., 2019). Northern Saskatchewan had the highest police-reported crime rate, violent crime rate, and Crime Severity Index (CSI) in Canada's north in 2013 (Allen \& Perreault, 2015). In fact, within the province, northern Saskatchewan had over four times the rate of homicides, over nine times the rate of major assault, and 8.6 times the rate of common assault compared to southern Saskatchewan (Allen \& Perreault, 2015); thereby, underscoring the high levels of crime in this region and the need for interventions designed to prevent and reduce violence. Accordingly, the NYVRP targeted youth (12-24 years of age) who were adjudicated or at risk in terms of violence and gang involvement. Participants were referred to the program by corrections, RCMP, and community sources and participation in the program was voluntary. The program was governed by an overarching Oversight Committee and local Advisory Committees with the participation of community agencies and stakeholders.

In line with best practices in program development recommending that interventions be informed by theory (Issel, 2004), the NYVRP was guided by three evidencebased models: the Youth Violence Reduction Partnership (YVRP; McClanahan et al., 2012), Re-Entry and Intensive Aftercare (Altschuler \& Armstrong, 2004), and Risk-NeedResponsivity (RNR; Andrews et al., 1990) models. Each of these models aim to reduce risk through rehabilitation, service provision, and intense supervision. Notably, the YVRP model was originally developed to reduce inner-city gun violence in Philadelphia and involved close supervision of high-risk youth participants from police and probation officers with emotional and practical support provided to the youth by street workers who served as mentors. Given the unique context in which the NYVRP was implemented (i.e., in rural, largely First Nation communities), some modification of the original models was required. One of the main adaptations made by the NYVRP was that the police did not offer strict supervision over the youth; instead, they adopted a friendly supervision model to maintain a positive relationship with youth rather than an adversarial relationship. In this model, police focused less on strict supervision and surveillance; rather, they worked closely with the NYVRP program staff and stakeholders to reduce the level of contact between the criminal justice system and the youth by helping them seek treatment for any mental health and cognitive needs they have as well as directing them to prosocial activities and networks through the NYVRP, which included the incorporation of cultural activities, Elders/mentors, and land-based teachings. The police also made efforts to build friendly relationships with the youth through informal communications on streets and collaborated with program staff to provide opportunities for youth to participate in recreational activities.
In addition to the friendly supervision model, the NYVRP emphasized risk management and rehabilitative strategies, arguably to a greater extent than the original YVRP model. With respect to risk management, supervision, and other interventions that reduce opportunities to engage in antisocial behaviors were employed by the criminal justice stakeholders of the program including the RCMP, correctional services, and criminal courts. These strategies and interventions included custodial sentences, court-ordered prohibitions (e.g., restricting the use of firearms or alcohol), curfews designed around high-risk times, contact restrictions (e.g., from victims and pro-criminal friends), and direct contact supervision standards involving program staff. Participants who were adjudicated were expected to maintain contact with their probation officers and follow all court-ordered conditions and sentences. In terms of rehabilitative programs, activities that targeted dynamic risks (e.g., employment/education, substance use, family circumstances, pro-criminal companions/ attitudes, and mental health issues linked to offending) were pursued. NYVRP staff used one-on-one contact with the youth to establish relationships and maintained frequent personal contact with them.

The risk levels of the youth were identified by using three risk assessment tools: Youth Level of Service/Case Management Inventory: Screening Version (YLS/CMI: SV; Hoge $\&$ Andrews, 2013), Problem-Oriented Screening Instrument for Teenagers (POSIT; Rahdert, 1991), and Center for Youth Wellness Adverse Childhood Experience-Questionnaire-Teen Version (ACE-Q; Harris \& Renschler, 2015). Youth must be assessed as being high risk to be eligible to participate in the NYVRP and any programming offered to youth was responsive to their risk levels and specific needs in line with the RNR framework. Based on the risk levels and needs identified through risk assessment tools, case plans were developed and implemented for each participant. The case plans were developed and revised by local Core Teams through an integrated case management approach during monthly meetings. The Core Teams were composed of program staff and key stakeholders, such as the police, corrections, education, and Elders. In the case plans, efforts were made to address the cultural and spiritual needs of the participants and make accommodations for those with mental health issues or cognitive disabilities (e.g., FASD, development learning disorders). Through the provision of supervision, support, and rehabilitation, it was anticipated that youth would acquire the knowledge and skills needed to reduce their criminogenic risk factors and ultimately lead to reduced physical violence, violence victimization, and gang-related activities. It was also anticipated that, through the building of stronger partnerships among local community, police, and corrections agencies via the collaborative aspects of the program, local capacity to address and reduce 
future potential violence and gang-related activities would be enhanced.

To determine the extent to which the NYVRP was effectively delivered and led to its anticipated outcomes (i.e., reduced violence and gang involvement among participants), process (Jewell et al., 2020) and outcome evaluations (Jewell et al., 2021) of the NYVRP were conducted. In the current paper, we will focus on the aspects of the evaluations that are specific to the policing elements of the program, with an emphasis on discussing the implications of these findings for Indigenous policing in Canada.

\section{Method}

Process and outcome evaluations were conducted to understand how the NYVRP was functioning on an annual basis and to assess whether the program's anticipated intermediate and long-term outcomes were achieved by the conclusion of the initiative. A mixed-methods design, involving a combination of qualitative and quantitative data, was employed in both steps. As the evaluation was taking place in predominantly First Nation communities, a participatory evaluation design framework was used to be respectful of the historical injustices to which they have been subjected (Stewart \& Dene, 2009) and to recognize the rights of these communities to own, control, access, and possess their data, which is a set of principles commonly referred to as OCAP( (FNIGC, 2007). Participatory approaches, with their focus on working directly with the individuals or groups who have a stake in a given study's outcomes, help ensure that First Nations are active participants in the evaluation process (Springett \& Wallerstein, 2008). As such, we invited the three NYVRP communities to participate in the evaluation activities including the evaluation design, data collection and analysis, and dissemination of findings. For instance, while planning the evaluation, we asked the Evaluation Advisory Committee (which included representatives from the communities) for guidance about the specific evaluation questions that should be asked in their communities; who should be asked to participate; and appropriate protocols to follow and methods to use. We also shared the evaluation findings with the Oversight and Advisory Committees (which also included representatives from the communities) and integrated their interpretations of the results into the final version of the report.

The components of the process and outcome evaluations of the NYVRP that are included in the current study are a community youth survey $(n=100)$, a participant survey $(n=7)$, semi-structured interviews with staff and stakeholders $(n=13)$, a community stakeholder survey $(n=25)$, and police-youth interactions data $(n=80)$. The quantitative survey data were analyzed using descriptive statistics (e.g., frequencies, means, standard deviations). Conversely, thematic analysis was used to analyze any qualitative survey data and the interview data. That is, the responses were analyzed for recurring themes and patterns (Boyatzis, 1998). Themes which represent the underlying concepts which describe and organize the data or offer an interpretation of it are presented in the results.

\section{Community Youth Survey}

To identify the self-reported crime rates and trust in the police among the community youth, some of the findings from the descriptive analysis on the community youth survey results are presented. The community youth survey was included in the evaluation of the program to understand the perceptions of the youth living in the communities to identify whether there is a continuous need for the NYVRP in the communities. Prior to completing the survey, participants were informed that the survey will ask about their experiences in their community to determine whether there is a need for programs like the NYVRP. The survey asked youth about their self-reported delinquency and gang involvement, substance abuse, antisocial/prosocial tendencies and behaviors, criminal thinking, gang involvement in their families, peer delinquency, negative peer influences, involvement in prosocial activities, parental supervision school attendance and success, and perceptions on the police and safety in their communities.

The survey was completed by 100 youth, approximately, equally distributed across the three communities involved in the initiative. The survey was handed out by program staff to youth attending community events in all three communities (e.g., Treaty Day celebrations) during May and June 2019. Youth who returned the survey were entered into a draw for a gift card (one draw was held per community). The survey was self-report and completed in hard copy (i.e., using pen or pencil). The majority of survey respondents were female (61\%). Respondents ranged in age from 12 to 27 years and had a mean age of 18 years. Most youth identified as heterosexual/straight (82.8\%), while others identified as bisexual $(10.8 \%)$, gay $(1.1 \%)$, lesbian $(1.1 \%)$, two-spirit $(1.1 \%)$, or other (3.2\%). Fourteen youth who completed the survey were also NYVRP program participants.

\section{Participant Survey}

To explore the youth's satisfaction with the program, a paper-based participant survey consisting of 17 questions about various aspects of the program was administered to youth in the second last month of the program. The survey was completed by 7 male youth during a site visit to Deschambault Lake in February 2020. We intended to collect additional participant surveys during site visits to Pelican 
Narrows and Sandy Bay planned for March 2020, but those were canceled due to travel restrictions stemming from the COVID-19 pandemic.

\section{Staff and Stakeholder Interviews}

Semi-structured telephone interviews were conducted with NYVRP staff and stakeholders $(n=13)$ to examine the NYVRP's program delivery and to assess stakeholders' perceptions of the outcomes they observed among the youth and communities involved in the program. Interviews ranged in length from 30 to $120 \mathrm{~min}$, with most interviews taking approximately $60 \mathrm{~min}$. Participants were from NYVRP program management and staff $(n=6)$, corrections $(n=4)$, RCMP $(n=1)$, schools $(n=11)$, and community programsmental health, addictions, and justice $(n=1)$.

\section{Community Stakeholder Survey}

A Community Stakeholder Survey was conducted online to explore program stakeholders' perceptions of, and experiences with, the NYVRP $(n=25)$ in 2020. A response rate of $46 \%$ was achieved, and the survey was completed by a cross-section of stakeholders that approximated various agencies' level of involvement in the program. Specifically, respondents came from the following sectors: Corrections $(n=7)$, Education $(n=6)$, Policing $(n=4)$, Health $(n=1)$, Administration $(n=2)$, Social Services $(n=1)$, and Chief \& Council $(n=1)$. The survey consisted of 26 self-report questions that examined the stakeholders' level of involvement in the NYVRP and their perceptions of the impact the NYVRP had on the program youth and their community.

\section{Police-Youth Interactions}

The data used in the analysis of the interactions between the NYVRP youth and the police were provided by the RCMP. The data included anonymized information on the police-youth encounter incidents; specifically, the dates and types of incidents as well as the role of the youth in the incidents (e.g., suspect, witness, victim). Only incidents for youth $(n=80)$ who were in the program for at least 6 months were included in the dataset and, for these youth, incidents that occurred one year prior to their entry into the NYVRP, during their participation in the program, and up to two years after they exited the program were provided. The dataset included 1943 incidents among 80 youth occurring between March 2016 and March 2020. In 1510 of these cases, the youth were the suspect or subject of the crime. In 116 of the cases, they were victims and, in 188 cases, they were the witness of the crime. In 129 cases, the role of the youth was not given in the data.
Descriptive data analyses were conducted on the police data to identify the changes in the number and frequency of police-youth contact throughout the years, the types of incidents, and the roles of the youth in the incidents. Because the data provided by the RCMP were anonymized, an analysis of pre- and post-program police-youth interactions could not be conducted. Instead, the data were categorized into four different timeframes: (1) pre-program: March 2016-March 2017; (2) Year 1: April 2017-March 2018; (3) Year 2: April 2018-March 2019; and (3) Year 3: April 2019-March 2020. An aggregate level analysis was conducted based on these time categories and by comparing the average number of police encounters that occurred each year. The average number of incidents was found through dividing the number of incidents by the number of youths for whom the data include corresponding police encounter information.

\section{Results}

\section{Community Youth Survey}

The Community Youth Survey solicited youth's perceptions $(n=100)$ about their perceived need for the NYVRP in their communities, as well as related factors, such as the nature of their relationship between the police and the extent to which they are involved in antisocial behavior. To examine youth's level of comfort and trust with the police, respondents were asked to rate how often they (a) were afraid of the police; and (b) trusted the police. Those who said that they were always or often afraid of police represented $23 \%$ of respondents. Further, $18 \%$ of the youth said they never trusted the police, whereas $32 \%$ sometimes trusted the police. Interestingly, approximately the same proportion of respondents that were never afraid of the police (52\%) always or often trusted the police (45\%). In terms of the respondents' comfort with calling the police if they are in trouble, $34 \%$ indicated that they were always comfortable. This rate slightly increases when they see someone else in trouble (38\%; see Table 1).

The youth who participated in the survey were also asked about their involvement in various delinquent behaviors. More than half of the youth indicated that they use drugs $(52 \%)$ and alcohol $(58 \%)$ and nearly half of them $(44 \%)$ got in trouble due to alcohol and drug use. Thirty-nine percent of the participants were arrested, and the majority of these youth $(36 \%)$ were charged with a crime. Bullying (39\%), property damage (28\%), and graffiti $(17 \%)$ were other types of delinquencies in which the youth were involved (see Fig. 1). Overall, the survey results pointed to high levels of antisocial behavior and some mistrust of, and discomfort with, the police. Together, these findings suggest that there was both a continued need for a community-based program like the NYVRP in the communities as an alternative to 
Table 1 Community youth perceptions of the police $(n=100)$

\begin{tabular}{llllr}
\hline & Never (\%) & $\begin{array}{l}\text { Some- } \\
\text { times (\%) }\end{array}$ & Often (\%) & Always (\%) \\
\hline Afraid of the police & 52 & 20 & 15 & 8 \\
Trust the police & 18 & 32 & 12 & 33 \\
Feel comfortable calling police if I am in trouble & 19 & 25 & 21 & 34 \\
$\begin{array}{l}\text { Feel comfortable calling the police if I see some- } \\
\text { one in trouble }\end{array}$ & 15 & 25 & 18 & 38 \\
\hline
\end{tabular}

Fig. 1 Percentage of youth selfreporting delinquency (\%)
Self-Reported Delinquency

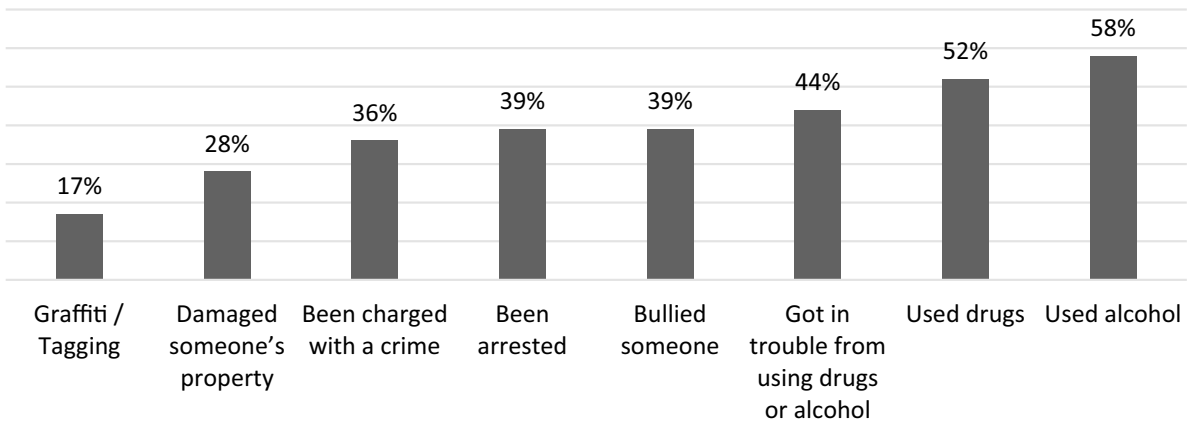

traditional justice methods and enhanced relationships with the police (which the NYVRP may be able to facilitate).

\section{Participant Survey}

Results from the NYVRP Participant Survey offered insight into the way in which the NYVRP helped the youth enroll in the program with respect to a number of outcome areas. Specifically, the youth believed the NYVRP helped them with a number of violence-related outcomes: $86 \%$ believed they were less involved in fights and violence, $86 \%$ perceived they were getting in less trouble with the police, $57 \%$ indicated that they were less involved in bullying, $43 \%$ selfreported being less involved in gangs, and 29\% indicated they were doing less tagging/graffiti. Youth also believed that the program helped them become more connected to their cultures. For instance, the youth self-reported that they were doing more cultural activities (86\%) and had stronger connections with Elders (74\%). One youth also noted that the program helped with speaking Cree. In addition, $43 \%$ of the youth indicated that the NYVRP helped them become more involved in recreational activities. Further, the youth perceived that the program helped with their familial and peer relationships $-86 \%$ reported stronger family relationships and $74 \%$ indicated they had more positive friends. In addition, $43 \%$ felt more supported by the community after participating in the program. Importantly, one youth indicated the program taught him how to help others. Youth also perceived improvements in their school performance and attendance. Here, $74 \%$ self-reported getting better grades and $57 \%$ were attending school more often. Finally, the youth indicated some improvements in their mental health and addictions, including having better coping skills (74\%), using drugs and alcohol less often (57\%), and having better mental health (43\%).

\section{Stakeholder and Staff Interviews and Open-Ended Survey Questions}

The thematic analysis of the qualitative data gathered from program stakeholders and staff through semi-structured interviews and open-ended survey questions revealed important aspects of the NYVRP specific to its friendly supervision model and police-youth-community relationships. Some of the themes identified from the interview and survey data are directly or indirectly related to the police approach within the NYVRP program model. The first theme presented (i.e., friendly supervision) speaks to the rationale for adopting a friendly supervision approach and the enactment of this approach. The subsequent themes (i.e., decreased violence, attitudes toward authority figures, and sustainability of outcomes) speak to the impact that the NYVRP had on its participants, especially as it relates to their antisocial behavior and interactions with the police.

\section{Friendly Supervision}

Throughout the NYVRP, there was an intentional focus on support and rehabilitation of the youth rather than on strict supervision. The remote geographic location of the 
communities played a significant role in the focus on support and rehabilitation provided by program staff rather than on a combination of support and strict supervision jointly provided by program staff, policing, and corrections (as described by the YVRP model). Focusing first on the RCMP, the detachments in the three communities were restricted by limited personnel, which prevented them from being able to strictly supervise the NYVRP youth in the communities. According to one interviewee, "we just don't have the people or the time to do that." This is not to say that the RCMP were uninvolved with the youth enrolled in the NYVRP, their interactions with youth tended to be more casual. According to one officer, "I would often stop, like if they were either on a call or just driving around, certain kids I would stop and chat with them." The RCMP also sponsored clinics or hosted activities intended to provide youth with the opportunity to learn life skills or participate in prosocial activities (e.g., life jacket safety clinics, Community Cadet Corps). It had been suggested by some stakeholders that the police had adopted a friendly supervision model in terms of their role in the NYVRP and that this was a unique adaptation of the NYVRP; however, RCMP stakeholders suggested that this "friendly policing" approach is fundamental to all policing.

Every place I've been in uniform that good relationship, that how are you doing today, that little chat, that's policing at the core, it's policing 101 ....It just naturally occurs with NVYRP, we didn't have to push anything. Not every member is not as open and comfortable but a lot are....and if you make those friendly relationships, that type of stuff helps you solve crime. (RCMP)

\section{Decreased Violence}

In the stakeholder interviews, one of the most emphasized outcomes of the NYVRP was a decrease in bullying, aggressive, and violent behavior. When asked in the interviews whether stakeholders perceived changes in this area, they considered this topic more broadly and included any type of antisocial/criminal activity in which the youth may be involved (e.g., mischief, breaking, and entering). A majority of staff and stakeholders commented that youth were "staying out of trouble now" and that many of the youth were "off the radar of the RCMP." RCMP stakeholders (in both the interviews and stakeholder survey) also perceived a decrease in the frequency of youth crime in the communities where the NYVRP was implemented and attributed these decreases to the NYVRP. In particular, one RCMP stakeholder attributed the program's success to continuing to work with the youth, even if they get into trouble after joining the program.

The RCMP have notified us that they are in a better situation with us working with them. They've been acting different and off the radar of the RCMP. (Program Staff)

I know that when we have a community incident, something happens in the community crime-wise, none of our youth are involved. (Program Staff)

Crime rate, especially with these youth, has dropped. (Community Stakeholder)

We've [the RCMP] had less and less interaction with youth...Here, youth crime barely comes on our radar...the NYVRP has quite a bit to do with that. It's not that they didn't get in trouble anymore, they still did, but the NYVRP helped lessen it. And the NYVRP helped them get back on track and get focused. So they didn't give up on them, and they do whatever they do that kept them focused and going in a different direction. Without that, our youth crime would have been much worse. Of course, it starts with drugs and alcohol, and then the assaults and property crime. And we're already starting to see it creep up. (RCMP)

In addition to reducing the frequency of crime, it was perceived that the severity of the crimes in which the NYVRP participants were involved had reduced following their participation in the program. It was also perceived by the RCMP that, when the youth do come into contact with the police, "they seem to be easier to deal with." The RCMP stakeholders in particular considered these to be positive outcomes of the program.

Well, I guess very bluntly it took some of the problems off our plate. We had a lot to deal with and it kept a lot of things from having us to deal with or, if it did, it was at a much lower level that it didn't have to take a lot out of us to deal with...some cases...could have really gone off the rails, [the youth are] decent to deal with, and they both could have gone in a different directions. And it would have been that way if the NYVRP wasn't here for a while to help steer him in another way. (RCMP)

\section{Attitudes Toward Authority Figures}

Several stakeholders perceived that some youth's attitudes toward the police have improved as a result of their participation in the NYVRP. In particular, it was observed that having opportunities to interact with the RCMP through the NYVRP reduced the hostility that youth had for the police and allowed them to develop a better understanding of the RCMP's role in the community in terms of keeping the community safe.

Because we got to work so closely with the RCMP that the kids, the kids began to respect the RCMP and what 
they did. They realized that....they were keeping them safe. Once they understood that, why they did their job, that sense of hostility that was there initially it kind of morphed into a friendship or a respect. (Program Staff)

\section{Sustainability of Outcomes}

While many stakeholders believed that the NYVRP had led to positive changes among the youth, there were concerns about the sustainability of these changes once the supports offered by the program are removed from the youth. For instance, RCMP detachments in two of the three communities noted an increase in criminal involvement during periods of time when NYVRP staff were unavailable and, therefore, less involved with the youth. It was understood that a return to high levels of criminal involvement was influenced by the fact that the youth had few, if any, other positive supports in the community. It had also been observed by the RCMP that some youth who were told that they were going to be exiting the program started to "get in trouble" again. It was believed that one of the reasons the youth started to get in trouble was that they could remain in the NYVRP.

The youth crime is quite low. I think NYVRP involvement has a lot to do with that. We notice a spike when there are less interactive opportunities between youth and NYVRP workers. (RCMP)

When the NYVRP was not running over Christmas 2018, we saw almost $100 \%$ criminal involvement/substance abuse with the youths that were not able to be engaged with almost every youth during this time was arrested as they had no positive supports in the community. (RCMP)

In the future, without the NYVRP, stakeholders believed that they would see youth crime start to rise again in their communities; however, some were optimistic that youth who had participated in the NYVRP would be able to maintain the positive gains they had made.

I think without it, we're going to see the youth go down hill. We're going to see the crime escalate again, because the youth, especially the males that I'd seen, the males, their criminal activity lessened big time. (Community Stakeholder)

I'm thinking the connection, the connection, if the program is gone, I think we're going to see the youth, not necessarily the ones that have been worked with already...the ones that have been worked with have gained a lot more insight and they are staying out trouble. I think they've set more positive goals for themselves. (Community Stakeholder)

\section{Community Stakeholder Survey}

The Community Stakeholder Survey further explored stakeholders' perceptions about the impact of the NYVRP on the youth and their community (see Table 2). Most respondents agreed or strongly agreed that, after joining the NYVRP, the youth were less involved in fights/violence (74\%), less involved in gangs $(65 \%)$, getting in less trouble with the police $(75 \%)$, were less involved in bullying (63\%), and were having stronger connections with community agencies and supports (73.7\%). Just over half of the respondents agreed or strongly agreed that the youth were using drugs or alcohol less often (52.7\%) and doing less tagging/graffiti (53\%) after participating in the program.

The Community Stakeholder Survey also examined respondents' interest and ability to collaborate with other agencies, as well the community's ability to cooperate with the RCMP and Corrections specifically (see Table 3). The majority of respondents indicated that participating in the

Table 2 Community stakeholder survey individual-level outcomes

\begin{tabular}{|c|c|c|c|c|c|}
\hline Item & $\begin{array}{l}\text { Strongly disagree } \\
(\%)\end{array}$ & Disagree (\%) & $\begin{array}{l}\text { Neither agree nor } \\
\text { disagree }(\%)\end{array}$ & Agree $(\%)$ & $\begin{array}{l}\text { Strongly } \\
\text { agree } \\
(\%)\end{array}$ \\
\hline Following rules or listening better & 5.3 & 5.3 & 5.3 & 84.2 & - \\
\hline More respectful & 5.0 & 5.0 & 5.0 & 70.0 & 15.0 \\
\hline Doing less tagging/graffiti & - & 10.5 & 36.8 & 31.6 & 21.1 \\
\hline Less involved in bullying & - & 15.8 & 21.1 & 42.1 & 21.1 \\
\hline Less trouble with the police & 5.0 & 5.0 & 15.0 & 55.0 & 20.0 \\
\hline Less involved in gangs & 5.0 & 5.0 & 25.0 & 30.0 & 35.0 \\
\hline Less involved in fights/violence & - & 10.5 & 15.8 & 42.1 & 31.6 \\
\hline More positive attitudes toward the police & - & 10.5 & 21.1 & 57.9 & 10.5 \\
\hline Use drugs or alcohol less often & 5.3 & - & 42.1 & 47.4 & 5.3 \\
\hline $\begin{array}{l}\text { Stronger connections with community agencies } \\
\text { and supports }\end{array}$ & - & 5.3 & 21.1 & 57.9 & 15.8 \\
\hline
\end{tabular}


Table 3 Community stakeholder survey community-level outcome items

\begin{tabular}{|c|c|c|c|c|c|}
\hline Item & $\begin{array}{l}\text { Strongly } \\
\text { disagree } \\
(\%)\end{array}$ & Disagree $(\%)$ & $\begin{array}{l}\text { Neither agree } \\
\text { nor disagree } \\
(\%)\end{array}$ & Agree $(\%)$ & $\begin{array}{l}\text { Strongly } \\
\text { agree }(\%)\end{array}$ \\
\hline Increased our community's ability to cooperate with corrections & - & - & 41.2 & 47.1 & 11.8 \\
\hline Increased our community's ability to cooperate with the police & - & 10.0 & 30.0 & 45.0 & 15.0 \\
\hline Increased my agency's ability to collaborate with other community agencies & - & 10.0 & 10.0 & 60.0 & 20.0 \\
\hline Increased my interest in collaborating with other agencies & - & - & 21.1 & 63.2 & 15.8 \\
\hline Had sustainable positive impacts on the community & - & 5.0 & 5.0 & 65.0 & 25.0 \\
\hline Increased our community's capacity to address gangs & - & 11.1 & 16.7 & 61.1 & 11.4 \\
\hline Increased our community's capacity to address youth violence & - & 5.6 & 5.6 & 66.7 & 22.2 \\
\hline
\end{tabular}

NYVRP increased both their interest and ability to collaborate-79\% agreed or strongly agreed that the NYVRP increased their interest in collaborating with other agencies to address violence in their community, while $80 \%$ agreed or strongly agreed that the NYVRP increased their ability to collaborate with other community agencies. Slightly lower levels of agreement occurred with respect to the community's increased ability to cooperate with the police and corrections. Here, $60 \%$ of respondents agreed or strongly agreed that the NYVRP led to increased community cooperation with the police and 59\% agreed or strongly agreed it led to increased cooperation with Corrections. Thus, the NYVRP did seem to stimulate some interest in, and increased ability to, collaborate with other agencies, as well as some slight improvements in terms of cooperating more with police and corrections.

\section{Police Encounters with NYVRP Participants}

Finally, the analysis of the police data examined the frequency of the NYVRP participants' encounters with the police to determine quantitatively if the program led to any decreases in police-reported crime (see Table 4). In the year before the program started, 23 participants had no encounters with police as suspect/subject, whereas 32 youth encountered the police between 1 and 3 times in the same year. There was a substantial decrease in the number of youths with no police encounters during the program years. In year 1 , there were 9 youth with no police encounters, whereas this number increased to 10 and 12 in years 2 and 3 , respectively. Similarly, there was an increase in the number of youths with very frequent encounter with police (i.e., $\geq 10$ times) throughout the program years when compared with the year before the program began.

The analysis of the RCMP data on police encounters with the NYVRP youth indicated that the average number of incidents per youth decreased in the first year of the program and remained stable in the second year (Fig. 2). However, there was an increase in the average number of incidents in the last year of the program. In the year before the program started, there were 5.89 incidents per youth where the NYVRP youth encountered the police as the suspect or subject (perpetrator) of the crime, and this number decreased to 4.76 when the program started but increased to 5.73 by Year 3 . These findings were consistent with stakeholders' qualitative perceptions that the effects of the NYVRP may wear off over time.

Our analysis also considered the breakdown of the incidents into broad categories of crime (i.e., crimes against persons and property) and incident categories based on the role of the youth in the incident (see Table 5). In total, there were 421 criminal incidents against persons perpetrated by the NYVRP youth and 515 incidents against property. In the last year of the program, there was a slight decrease in crimes against property perpetrated by the NYVRP youth; however, crimes against persons continued to increase in the same year. Further analysis of the types of crime revealed that 68 out of 80 youth were involved in both crimes against persons and property as subject or suspect of the crime. Seven participants were involved only in crimes against property and the same number of participants were only involved in crimes against persons.
Table 4 Frequencies of policeyouth encounter as suspect/ subject of crime per year $(n=80)$

\begin{tabular}{lllccc}
\hline & Never $(n)$ & $1-3$ times $(n)$ & $4-6$ times $(n)$ & $7-9$ times $(n)$ & $\geq 10$ times $(n)$ \\
\hline $\begin{array}{l}\text { Pre-Program } \\
\quad \text { (1 year) }\end{array}$ & 23 & 32 & 8 & 8 & 9 \\
Year 1 & 9 & 31 & 21 & 9 & 10 \\
Year 2 & 10 & 27 & 22 & 8 & 13 \\
Year 3 & 12 & 33 & 8 & 12 & 15 \\
\hline
\end{tabular}


Fig. 2 Average number of police encounters of youth as suspect/subject (per year)
Average Number of Incidents per Youth

(NYVRP Youth - Police Contact)

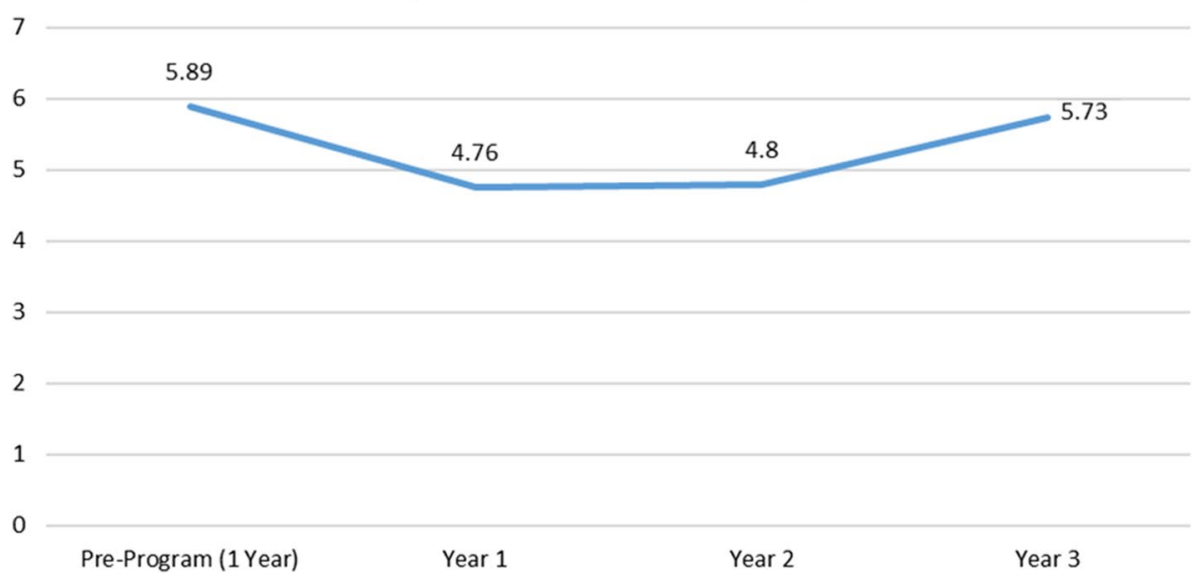

There was also an increase in the number of victimizations the program youth experienced throughout the years. The number of cases where the youth was in the witness role was also close to the number victimizations across the four years. The majority of the incidents where the program youth were victims were crimes against persons. Overall, these findings suggest that youth involved in the NYVRP may encounter the police both as perpetrators and victims of crime.

Table 5 Roles of the youth in the police-youth encounter incidents per year

\begin{tabular}{|c|c|c|c|c|c|}
\hline $\begin{array}{l}\text { Role of the } \\
\text { youth }\end{array}$ & $\begin{array}{l}\text { Pre-pro- } \\
\text { gram } \\
(n)\end{array}$ & Year $1(n)$ & Year $2(n)$ & Year $3(n)$ & Total (n) \\
\hline \multicolumn{6}{|c|}{ Crimes against persons } \\
\hline $\begin{array}{l}\text { Suspect/ } \\
\text { subject }\end{array}$ & 80 & 94 & 98 & 149 & 421 \\
\hline Victim & 21 & 28 & 24 & 33 & 106 \\
\hline Witness & 26 & 23 & 31 & 25 & 105 \\
\hline \multicolumn{6}{|c|}{ Crimes against property } \\
\hline $\begin{array}{l}\text { Suspect/ } \\
\text { subject }\end{array}$ & 121 & 154 & 133 & 107 & 515 \\
\hline Victim & 1 & 2 & 2 & 2 & 7 \\
\hline Witness & 6 & 8 & 8 & 12 & 34 \\
\hline \multicolumn{6}{|l|}{ Total } \\
\hline $\begin{array}{l}\text { Suspect/ } \\
\text { subject }\end{array}$ & 201 & 248 & 231 & 256 & 936 \\
\hline Victim & 22 & 30 & 26 & 35 & 113 \\
\hline Witness & 32 & 31 & 39 & 37 & 139 \\
\hline
\end{tabular}

\section{Discussion}

The friendly police supervision model was one of several components of the NYVRP program. Although the outcomes of this program cannot be solely attributed to the policing component, the findings of the process and outcome evaluation that are presented in this study provided evidence concerning the relevance of the friendly police supervision model with the overall goals of the program as well as the effectiveness of the program for reducing violence in the communities and indicated the ongoing need to develop better relationships between the police and Indigenous communities and youth.

A comparison of the findings in the community youth survey and the national and provincial youth crime rates suggests that there is a very high delinquency rate among the youth living in the three communities (i.e., $36 \%$ of the participants self-reported that they were charged with a crime). According to a 2016 report by the Department of Justice on youth criminality in Canada (Department of Justice, 2016), based on police records, the overall crime rate among Canadian youth is $4 \%$ and the rate is $11 \%$ for youth in Saskatchewan (excluding traffic and federal statute offences). An important finding in the police encounters data was the high rates of victimization of the program youth. More than two-thirds of the program participants were a victim of a crime at least once between 2016 and 2020. This rate is higher than the victimization rate among the youth in the NYVRP communities based on the Community Youth Survey where $47 \%$ of youth who completed the survey reported they had been physically assaulted in their communities. The high levels of victimization both among the NYVRP participants and the community youth can be attributed to the high level of criminality and gang involvement in the communities. Research has shown that the youth who are at high risk in terms of violent behaviors and who are involved 
in the juvenile justice system are at especially high risk for exposure to violence (Kretschmar et al., 2017). In line with the previous research, the fact that almost all NYVRP clients are at high risk partially explains the high rates of victimization among them.

Trust in police and the criminal justice system as a whole is an important factor that affects youth's decisions to become involved in criminal activities or relapse. Previous research has found links between perceptions of justice system fairness among adolescents and their likelihood of recidivism. That is, those who perceive the justice system to be fair have lower rates of recidivism (Mulvey \& Schubert, 2012). In our study, $33 \%$ of the community youth participants reported that they always trust the police and $34 \%$ of them reported they feel comfortable calling the police if they are in trouble. These findings are close to the national figures on trust in police in Canada. A recent national survey found that the $36 \%$ of the youth aged between 15 and 24 has a great deal of confidence in Canadian police (Ibrahim, 2020). This rate is lower among Indigenous (30\%) and First Nations (27\%) people. The high self-reported criminality and delinquency rates of the community youth and the low level of trust of the youth in police indicate a need for a novel approach to policing in Indigenous communities.

The NYVRP program delivery model focused more on support and rehabilitation rather than on strict supervision by police and probation officers. The goal of the program was to prevent violence and other related problems among the program youth, which should, therefore, reduce contact between the youth and the criminal justice system. The data on police encounters of the participants revealed that, when the average number of incidents are considered, there was a considerable reduction in police encounters in the first two years of the program when compared with the year before the program. There was an increase in the number of encounters in the last year of the program, and there were more youth who had very high frequency of police encounters (i.e., more than 10 times) throughout the program years compared to the year before the program began. This trend was mostly due to the increase in the crimes against persons, whereas crimes against property steadily decreased. Given that the last year of data largely reflected data from youth who had already exited the program, it may be that the effects of participating in the program had started to dissipate by this time. That is, the lower average number of encounters in Years 1 and 2 when the majority of youth were actively participating in the program may indicate that the NYVRP reduces youth's involvement with the police while youth are active in the program or in the short-term following program completion but may be less effective at reducing police encounters in the long term.

Results from the Community Stakeholder Survey suggested that NYVRP youth had more positive attitudes toward the police after their involvement in the program. Youth were also expected to develop more prosocial attitudes and interpersonal skills. In line with this outcome area, staff and stakeholders perceived that youth were communicating better, developing compassion, more respectful, and beginning to understand the importance of rules. Stakeholders' perceptions also suggested that the NYVRP led to reduced violence and involvement with gangs and fewer interactions with the police. The findings in the semi-structured interviews and open-ended survey questions corresponded with the quantitative findings. The friendly supervision approach adopted in the NYVRP program was perceived as a fundamental component specifically by the police and correctional stakeholders, and its positive impacts on the youth's relationship with the police and attitudes toward authority figures were emphasized by other stakeholders. Despite the limited sample in the NYVRP Participant Survey, findings indicated that the participants' perceptions on how the NYVRP helped the youth decrease their involvement in violence, delinquency, and substance use while developing their connection to their cultures, families, and prosocial peers.

Although the evaluation findings provided insights into the relevance and effectiveness of the overall approach and policing model in the NYVRP program, some limitations in data collection need to be noted. First, the majority of data collection activities coincided with the onset of the COVID19 pandemic. Some planned site visits for data collection activities such as participant survey were canceled due to the travel restrictions. We also believe that the lower rate of stakeholders agreeing to participate in stakeholder interviews was, in part, due to the new and unexpected priorities that emerged for these individuals related to the pandemic. In addition to the limitations associated with the pandemic, the responses provided by stakeholders in the interviews and Community Stakeholder Survey may have been affected by a social desirability bias. Given that this was a pilot project, many of the stakeholders spoke of wishing for the NYVRP's continuation and, as a result, may have emphasized the positive aspects of the program (including the outcomes it achieved) to encourage its continuation.

\section{Implications for Indigenous Policing}

Based on their review of the challenges in Indigenous policing in Canada, Ruddell and Kiedrowski (2020) concluded that "it may be time to establish a new national policing model designed to better meet the needs and demands of Indigenous communities and based on the lessons learned in the past three decades of the FNPP" (p. 152). The findings in our evaluation of the NYVRP program and lessons learned from the best practices in other jurisdictions can inform the policies in the development of this new policing model. 
One of the most remarkable findings in this study was that the local police noticed a spike in the criminal involvement of the youth when there are fewer interactive opportunities between the youth and NYVRP workers, such as the period when the NYVRP was not running over Christmas time. This indicates the need for a sustainable policing and community service approach which incorporates the friendly supervision model as well as other components of the NYVRP, such as continuous support from program staff and community agencies, cultural activities and learnings, and engagement of community partners (Jewell et al., 2020, 2021). NYVRP program staff maintained a close relationship both with the youth and the RCMP, which created the opportunity for them to support the youth both before they got in trouble and when they got in trouble. Greater investment in community-based and culturally sensitive programs like NYVRP in which the police are a part of the program, but not a driving force or enforcer of the program, may be a more appropriate approach to policing and reducing crime in Indigenous communities.

The evidence-based evaluations of programs like the NYVRP can help to understand the unique characteristics and needs of Indigenous communities in Canada when adopting best practices and lessons learned from other jurisdictions. A review of Indigenous policing models implemented in the United States, Australia, and New Zealand identified five common best practices: (1) prioritizing a community-based policing philosophy; (2) emphasis on the improvement of Indigenous police relations; (3) support of local crime management initiatives; (4) building local partnerships with community stakeholders to reduce crime; and (5) promoting a needs-based approach to police service delivery (Jones et al., 2014). Indigenous people in these countries and Canada have common troubled historical experiences with the criminal justice system including systemic racism, overrepresentation in the incarcerated populations, over-policing, and under-policing (Cesaroni et al., 2019; Nielsen \& Robyn, 2003; Perry, 2009; Roberts \& Melchers, 2003). Similar to Indigenous communities in Canada, their relationships with the police suffer from the ongoing negative effects of these adverse experiences. Therefore, in light of the recommendations derived from the evaluation of Canadian programs like the NYVRP, the lessons learned from the best practices in the United States, Australia, and New Zealand in terms of Indigenous policing can be applicable in Canada. In this context, the five themes found in the Jones et al.'s (2014) review will be discussed below in light of our evaluation findings.

\section{Community-Based Policing}

The Eurocentric crime-control approach in policing which basically aims to prosecute, punish, and deter offenders by putting an emphasis on a paramilitary bureaucracy does not address the needs of the Indigenous communities, especially those living in rural areas (Jones et al., 2014; Perry, 2009). A community-based policing approach which is based on principles like responsibility, accountability, and interdependency is key to successfully repairing the troubled history and eliminate the adverse experiences between the Canadian police and Indigenous communities (Depew, 1992). As seen in the NYVRP program, a friendly police supervision model accompanied with multi-faceted and culturally appropriate programming might be the ideal approach for police to gain the trust of Indigenous people in Canada.

\section{Improved Relationships with Indigenous Communities}

One of the recommendations to improve Indigenous policing provided in the final report of the National Inquiry into Missing and Murdered Indigenous Women and Girls (2019) was building capacity and partnership with other agencies working in Indigenous communities to address crime and related social problems. The outcomes of the friendly supervision model and overall community-based approach in the NYVRP provide evidence that supports this recommendation. Both the community stakeholder survey and interviews with community stakeholders indicated that the NYVRP program increased the communities' ability to cooperate with the police, address violence and gang issues, and help youth develop more positive attitudes toward the police. With an enhanced partnership with the community agencies and community-based programs, the police can enhance their capacity to work in Indigenous communities. This approach becomes especially important when it comes to dealing with youth crime and delinquency because the Indigenous population in Canada is much younger and growing at a much higher rate than the non-Indigenous population (Statistics Canada, 2018). Therefore, the future of the relationship between the Canadian police and Indigenous people depends on initiatives that will win the hearts and minds of the Indigenous youth.

\section{Support of Local Crime Management Initiatives}

In New Zealand and Australia, an increasing presence of local justice initiatives that aim to reduce crime presents new perspectives in Indigenous policing. Non-coercive intervention strategies directly led by the Indigenous communities in these countries such as night patrols (an initiative of volunteers from Julalikari community to patrol neighborhoods and respond to conflicts before the formal justice system intervenes) and Neighborhood Support (a local New Zealand volunteer organization that aims to reduce local crime) promote the ownership of crime prevention duty by the communities while implementing culturally appropriate 
conflict resolution strategies (Jones et al., 2014). These initiatives allow the decision-makers to institutionalize "the Indigenous voice into local policy development and implementation" (Jones et al., 2014, p. 111). A similar approach can be adopted in Canada by institutionalizing the friendly supervision model of the NYVRP in partnership with the local initiatives.

\section{Local Partnerships with Community Stakeholders}

Partnership with local stakeholders is a key element of community policing as it allows for building an interdependent policing approach and providing a tailored police response in Indigenous communities (Jones et al., 2014). That is, thanks to these partnerships, police and local stakeholders can build a common understanding on the safety goals and objectives of the community and facilitate cooperation to achieve them. The majority of NYVRP stakeholders reported that the program increased their agencies' ability to collaborate with other community agencies, as well as their interest in collaborating with other agencies in reducing violence in their communities. One important component of the NYVRP was the Core Teams in each community which met monthly to develop and monitor care plans through an integrated case management process. These teams allowed for enhanced information sharing among stakeholders, including the police, about mutual clients and possible programming opportunities for them. Police representatives also participated in oversight and local advisory committees which provided guidance and direction for the delivery of the NYVRP. Through bodies established within communitybased programs, police working in Indigenous communities can have the opportunity to develop partnerships with community stakeholders and achieve mutual safety goals through these partnerships.

\section{Needs-Based Approach to Service Delivery}

Indigenous communities in Canada have diverse cultures, languages, and characteristics. Each community might have their unique needs due to these differences. Understanding the community-level and individual-level needs and cultural characteristics of Indigenous peoples is another key aspect for developing a successful Indigenous policing model. In a recent study on the interview practices of 37 Canadian police officers working in a predominantly Indigenous region in northern Canada, officers reported that cultural differences impacted their interviewing performance, and they could only 'sometimes' (50\%) or 'rarely' (21\%) elicit a full account from interviewees (Chenier et al., 2020). Half of the officers attributed their difficulties in obtaining the full accounts of victims and witnesses to problems with language barriers and communication.
The NYVRP program model was responsive to the specific needs and risk levels of the participants. For instance, efforts were made to incorporate the cultural and spiritual needs of First Nations participants and make accommodations for those with mental health issues or cognitive disabilities (e.g., FASD, development learning disorders). Through the provision of supervision, support, and rehabilitation, it was anticipated that youth would acquire the knowledge and skills needed to reduce their criminogenic risk factors. Importantly, the outcome evaluation indicated that these objectives were achieved. Also, the NYVRP adopted a strengths-based approach to reduce the risk of violent offending by offering individualized interventions to build upon each youth's strengths and to increase their connectedness to their culture. In doing so, their various criminogenic risks and needs (i.e., antisocial cognitions, attitudes, and behaviors; education; employment; mental health and addictions; and prosocial recreational activities) were ameliorated. Through an enhanced engagement with Indigenous culture and community, the police can better understand these needs and implement appropriate practices.

\section{Conclusion}

A new national policing model is needed to address the safety and security needs of Indigenous communities based on the lessons learned from current practices, evidencebased programs, and best practices in other jurisdictions. The literature on Indigenous policing in Canada is far from being conclusive in terms of understanding "what works." An effective way of developing a new policing framework is examining the outcomes of community-based programs implemented across Canada to reduce crime and violence among Indigenous communities and enhance the resilience of these communities against violence and other criminal problems. Policing is one of the most important components of these programs and the role of police either directly or indirectly affects the outcomes of these programs. The existence of the police as an established entity in every community might enable the sustainability of the impacts of those programs in Indigenous communities and maintain the best practices that are found effective through program evaluation and research studies. The NYVRP was one such program implemented in three predominantly Indigenous communities in northern Saskatchewan to reduce violence and gang involvement among the youth through rehabilitation, service provision, and friendly supervision.

As shown in the current study, the friendly supervision model implemented in the NYVRP helped with reducing violence, as well as with increasing the resilience and capacity of participants, community agencies, and the community as a whole against violence and gang problems. These 
findings should be interpreted by synthesizing the particular outcomes found in this study with the outcomes of other programs and initiatives that are funded and implemented at federal, provincial, and local levels, as well as the best practices on Indigenous policing in the United States, Australia, and New Zealand. A global understanding and framework on Indigenous policing can be developed based on the synthesis of the outcomes of evidence-based programs like NYVRP and best practices in Canada and other countries.

It was announced by the federal government in 2018 that $\$ 813.7$ million will be invested in the safety and security of Indigenous communities within five years (Public Safety Canada, 2018). In 2015, the federal government signed 185 police service agreements with Indigenous communities (Public Safety Canada, 2015). The Community-Based Justice Fund established within the Department of Justice currently funds 197 community-based programs that serve over 650 communities to help reduce the rates of crime and incarceration among Indigenous people (Department of Justice, 2020). Research should examine the effectiveness, strengths, gaps, and challenges of these programs to inform the policies on developing a new Indigenous policing model. A systematic review of program evaluations on these community-based justice and public safety programs and policies needs to be conducted to draw a comprehensive conclusion about "what works" and understand the diverse needs of Indigenous communities in terms of policing and public safety.

Funding This study was supported by Ministry of Justice-Saskatchewan.

\section{Declarations}

Conflict of interest On behalf of all authors, the corresponding author states that there is no conflict of interest.

\section{References}

Allen, M., \& Perreault, S. (2015). Police-reported crime in Canada's provincial north and territories, 2013. Juristat, catalogue no. 85-002-x. Ottawa, ON: Statistics Canada.

Altschuler, D. M., \& Armstrong, T. L. (2004). Intensive juvenile aftercare reference guide. Juvenile Reintegration and Aftercare Center.

Andrews, D. A., Bonta, J., \& Hoge, R. D. (1990). Classification for effective rehabilitation: Rediscovering psychology. Criminal Justice and Behavior, 17, 19-52.

Boyatzis, R. E. (1998). Transforming qualitative information: Thematic analysis and code development. Sage.

Cesaroni, C., Grol, C., \& Fredericks, K. (2019). Overrepresentation of indigenous youth in Canada's criminal justice system: Perspectives of indigenous young people. Australian \& New Zealand Journal of Criminology, 52(1), 111-128. https://doi.org/10.1177/ 0004865818778746

Chenier, K., Milne, R., Shawyer, A., \& Snook, B. (2020). Police victim and witness interviewing in a northern Canadian territory:
Measuring perceptions and practice. Journal of Police and Criminal Psychology. https://doi.org/10.1007/s11896-020-09417-8

Chouinard, J. A., \& Cousins, J. B. (2007). Culturally competent evaluation for aboriginal communities: A review of empirical literature. Journal of Multidisciplinary Evaluation, 4, 40-57.

Department of Justice. (2016). Youth criminal justice in Canada: A compendium of statistics. Department of Justice Canada. Retrieved May 18, 2021, from http://publications.gc.ca/colle ctions/collection_2018/jus/J4-58-2016-eng.pdf

Department of Justice. (2020). Community-Based Justice Fund. Retrieved May 25, 2021, from https://www.justice.gc.ca/eng/ fund-fina/acf-fca/ajs-sja/cf-pc/index.html

Depew, R. (1992). Policing native communities: Some principles and issues in organizational theory. Canadian Journal of Criminology, 34(4), 461-478.

First Nations Information Governance Centre. (2007). OCAP: Ownership, Control, Access and Possession. Sanctioned by the First Nations Information Governance Committee, Assembly of First Nations. National Aboriginal Health Organization.

Freeze, C. (2019). More than one-third of people shot to death over a decade by RCMP officers were Indigenous. Retrieved April 14, 2021, from https://www.theglobeandmail.com/canada/artic le-more-than-one-third-of-people-shot-to-death-over-a-decadeby-rcmp/

Graham, J. (2020, June 25). Canada confronts racism in police in wake of indigenous deaths. Reuters. Retrieved April 14, 2021, from https://www.reuters.com/article/us-canada-indigenouspolice-trfn-idUSKBN23W00F

Harris, N. B., \& Renschler, T. (2015). Center for Youth Wellness ACE-Questionnaire (CYW ACE-Q Child, Teen, Teen SR). Center for Youth Wellness.

Hoge, R. D., \& Andrews, D. A. (2013). The Youth Level of Servicel Case Management Inventory: Screening Version. Manual and scoring key. Multi-Health Systems.

Ibrahim, D. (2020). Public perceptions of the police in Canada's provinces, 2019. Juristat. Retrieved May 18, 2021, from https:// www150.statcan.gc.ca/n1/en/pub/85-002-x/2020001/article/ 00014-eng.pdf?st=hCIPhlJ5

Issel, L. M. (2004). Health program planning and evaluation. Jones and Bartlett Publishers.

Jewell, L. M., Akca, D., Mulligan, S., \& Wormith, J. S. (2020). Northeast Youth Violence Reduction Partnership (NYVRP) process evaluation: April 2015-March 2019. Centre for Forensic Behavioural Science and Justice Studies-University of Saskatchewan. (Report prepared for the Saskatchewan Ministry of Justice - Corrections and Policing.)

Jewell, L. M., Akca, D., Mulligan, S., \& Wormith, J. S. (2021). Northeast Youth Violence Reduction Partnership (NYVRP) Final Evaluation: April 2019-March 2020. Centre for Forensic Behavioural Science and Justice Studies-University of Saskatchewan. (Report prepared for the Saskatchewan Ministry of Justice - Corrections and Policing)

Jewell, L. M., Mulligan, S., \& Wormith, J. S. (2019). Northeast Youth Violence Reduction Partnership (NYVRP) Formative Evaluation: April 2015-March 2018. Centre for Forensic Behavioural Science and Justice Studies-University of Saskatchewan.

Jones, N. A., Ruddell, R., Nestor, R, Quinn, K., \& Philips, B. (2014). First nations policing: A review of the literature. Collaborative Centre for Justice and Safety. Retrieved May 10, 2021, from https://www.justiceandsafety.ca/rsu_docs/aboriginal-policing--complete-with-cover.pdf

Kretschmar, J. M., Tossone, K., Butcher, F., \& Flannery, D. J. (2017). Patterns of poly-victimization in a sample of at-risk youth. Journal of Child \& Adolescent Trauma, 10(4), 363-375. https://doi. org/10.1007/s40653-016-0109-9 
LeBeuf, M. (2011). The role of the Royal Canadian Mounted Police during the Indian residential school system. Royal Canadian Mounted Police.

McClanahan, W. S., Kauh, T. J., Manning, A. E., Campos, P., \& Farley, C. (2012). Illuminating solutions: The Youth Violence Reduction Partnership. Public/Private Ventures.

Monchalin, L. (2016). The colonial problem: An indigenous perspective on crime and injustice in Canada (Illustrated). University of Toronto Press.

Mulvey, E. P., \& Schubert, C. A. (2012). Some initial findings and policy implications of the pathways to desistance study. Victims and Offenders, 7(4), 407-427.

National Inquiry into Missing and Murdered Indigenous Women and Girls. (2019). Reclaiming power and place: The final report of the National Inquiry into Missing and Murdered Indigenous Women and Girls. Retrieved May 10, 2021, from https://www.mmiwgffada.ca/wp-content/uploads/2019/06/Final_Report_Vol_1b.pdf

Nielsen, M. O., \& Robyn, L. (2003). Colonialism and Criminal Justice for Indigenous Peoples in Australia, Canada, New Zealand and the United States of America. https://kuscholarworks.ku.edu/handle/ $1808 / 5791$

Perry, B. (2009). Policing race and place in Indian country: Over- and under-enforcement. Lexington Books.

Public Safety Canada. (2015). Policing in Indigenous Communities. Retrieved May 25, 2021, from https://www.publicsafety.gc.ca/cnt/ cntrng-crm/pleng/brgnl-pleng/index-en.aspx

Public Safety Canada. (2016). 2014-2015 evaluation of the First Nations policing program. Author.

Public Safety Canada. (2018). \$291.2 million to be invested in the safety and security of Indigenous communities. Retrieved May 25, 2021 from https://www.canada.ca/en/public-safety-canada/ news/2018/01/_291_2_million_tobeinvestedinthesafetyandsecu rityofindigenouscom.html
Public Safety Canada. (2021). Departmental Plan 2021-2022. Retrieved May 10, 2021, from https://www.publicsafety.gc.ca/cnt/ rsrcs/pblctns/dprtmntl-pln-2021-22/dprtmntl-pln-2021-22-en.pdf

Rahdert, E. (1991). Problem oriented screening instrument for teenagers (POSIT). European Monitoring Centre for Drugs and Drug Addiction. Retrieved from http://www.emcdda.europa.eu/html. cfm/index4439EN.html

Roberts, J., \& Melchers, R. (2003). The Incarceration of aboriginal offenders: Trends from 1978 to 2001. Canadian Journal of Criminology and Criminal Justice, 45(2), 211-242. https://doi.org/10. 3138/cjccj.45.2.211

Ruddell, R., \& Kiedrowski, J. (2020). Reforming Indigenous policing: Understanding the context for change. Journal of Community Safety and Well-Being, 5(4), 144-155. https://doi.org/10.35502/ jcswb. 168

Ruddell, R., \& Lithopoulos, S. (2013). Aboriginal policing in rural Canada: Establishing a research agenda. International Journal of Rural Criminology, 2(1),101-125. https://doi.org/10.18061/ $1811 / 58845$

Springett, J., \& Wallerstein, N. (2008). Issues in participatory evaluation. In Minkler, M. \& Wallerstein, N, (Eds.), Community-based participatory research for health: From process to outcomes. San Francisco: Jossey-Bass.

Statistics Canada. (2018). First Nations People, Métis and Inuit in Canada: Diverse and Growing Populations. Retrieved May 20, 2021, from https://www150.statcan.gc.ca/n1/en/pub/89-659-x/ 89-659-x2018001-eng.pdf?st=csXwzrLA

Stewart, S. L., \& Dene, Y. (2009). Participatory action research: Exploring indigenous youth perspectives and experience. Journal or the Indigenous Studies Network, 20(3), 1-42. 